\title{
WATER ABSORPTION AND HYDROTHERMAL PERFORMANCE OF PHBV/SISAL BIOCOMPOSITES
}

\author{
J.D. Badia ${ }^{1,2}$, T. Kittikorn ${ }^{3,4}$, E. Stromberg ${ }^{3}$, L. Santonja-Blasco ${ }^{1,5}$, A. Martínez-
} Felipe $^{1,6}$, A. Ribes-Greus ${ }^{1}$, M. Ek ${ }^{2}$, S. Karlsson ${ }^{3,7, *}$

This is an open-access version, according to http://www.sherpa.ac.uk/romeo/issn/0141-3910/

Full text available at https://www.sciencedirect.com/science/article/pii/S014139101400158X

DOI: https://doi.org/10.1016/j.polymdegradstab.2014.04.012

Please, cite it as:

J.D. Badia, T. Kittikorn, E. Stromberg, L. Santonja-Blasco, A. Martínez-Felipe, A. Ribes-Greus, M. Ek, S. Karlsson. Water absorption and hydrothermal performance of phbv/sisal biocomposites. Polymer Degradation and Stabiliy, 2014;108:166-174

\footnotetext{
${ }^{1}$ Instituto de Tecnología de Materiales (ITM), UniversitatPolitècnica de València (UPV).

Camino de Vera s/n, 46022, València, Spain

2 Departament d’ Enginyeria Química. EscolaTècnica Superior d’ Enginyeria. Universitat de

València. Av. de la Universitat, s/n,46100, Burjassot, Spain

${ }^{3}$ Department of Fiber and Polymer Technology, Kungliga Tekniska Högskolan.Teknikringen 56-

58, SE 10044 Stockholm, Sweden

4 Department of Materials Science and Technology,

Faculty of Science, Prince of Songkla University, Songkhla, 90112, Thailand

5 Department of Chemical and Biomedical Engineering, FAMU-FSU College of Engineering, 2525 Pottsdamer St, Tallahassee, FL 32310-6046, United States

${ }^{6}$ Departamento de Química Orgánica, Facultad de Ciencias, Instituto de Ciencia de Materiales de Aragón (ICMA), Universidad de Zaragoza-CSIC, Pedro Cerbuna, Zaragoza 50009, Spain

${ }^{3}$ University of Skövde. Högskolevägen 1, 54128 Skövde, Sweden
}

* Corresponding author: Professor Sigbritt Karlsson, e-mail: sigbritt.karlsson@his.se 


\title{
WATER ABSORPTION AND HYDROTHERMAL PERFORMANCE OF PHBV/SISAL BIOCOMPOSITES
}

\author{
J.D. Badia, T. Kittikorn, E. Stromberg, L. Santonja-Blasco, A. Martínez-Felipe, A. \\ Ribes-Greus, M. Ek, S. Karlsson
}

\begin{abstract}
The performance of biocompositesof polyhydroxybutyrate-co-valerate (PHBV) and sisal fibre subjected to hydrothermal tests at different temperatures above the glass transition of PHBV $\left(T_{H}=26,36\right.$ and $\left.46{ }^{\circ} \mathrm{C}\right)$ was evaluated in this study. The influences of both the fibre content and presence of coupling agent were focused. The water absorption capability and water diffusion rate were considered for a statistical factorial analysis. Afterwards, the physico-chemical properties of water-saturated biocomposites was assessed by Fourier-Transform Infrared Analysis, Size-Exclusion Chromatography, Differential Scanning Calorimetry and Scanning Electron Microscopy. It was found that the diffusion rate increased withboth temperature and percentage of fibre, whereas the amount of absorbed water was only influenced by fibre content. The use of coupling agent was only relevant at the initial stages of the hydrothermal test, giving an increase in the diffusion rate. Although the chemical structure and thermal properties of water-saturated biocomposites remained practically inherent to hydrolytical degradation, the physical performance was considerably affected, due to the swelling of fibres, which internally blow-up the PHBV matrix, provoking cracks and fibre detachment.
\end{abstract}

\section{Keywords}

Hydrothermal degradation; biocomposites; polyhydroxybutyrate-co-valerate (PHBV); lignocellulosic fibres; sisal; statistical factorial analysis (SFA) 


\section{Introduction}

The use of bio-based composites like lignocellulosic fibres/polymer composites as an alternative materials are continuously increasing in several applications such as automobile manufacturing, packaging, construction or household and agricultural equipments. Polyhydroxybutyrate-co-valerate (PHBV) is a sustainable polyester of the family of polyalkanoates which is produced by bacterial microorganisms. Although it is not widely exploited in consumer markets due to its high cost, it is still an interestingly attractive polymer as compared to conventional plastics [1].

The use of lignocellulosic fibres such a sisal fibre to reinforce PHBV biocomposites has the advantage of reducing the production costs due to low price of cellulose fibre. Furthermore, it is also environmentally friendly material which is derived from renewable resources and biodegradable at the end of life time as PHBV. Nevertheless, a main problem of using cellulose fibres in polymers is the inherent hydrophilicity of the fibres which consequently affects to reduce the reinforcement effect. In order to overcome this fact, surface modifications of fibre such as esterification [2], silanization [2-4] or maleic anhydride (MA) as coupling agent [2-3, 5-8]are used.

In order to warranty the durability on PHBV biocomposites, the previous knowledge about the influence of the ambient agents on their macromolecular properties is necessary. In this sense, hydrothermal tests at temperatures above the glass transition stands out as an accelerated procedure to simulate the performance of PHBV subjected to the synergic influence of water and temperature [9-11] .Literature reports studies of hydrothermal testing at $36{ }^{\circ} \mathrm{C}$, in order to model human body conditions on biopolymers such as polylactide and PHBV and their composites and blends[12-17]. In this work, the temperature span was extended to $26^{\circ} \mathrm{C}$, and $46^{\circ} \mathrm{C}$ in order to simulate different ambient conditions: e.g. $26^{\circ} \mathrm{C}$ may represent ambient temperature that can be found in agricultural yards, since an likely application of these PHBV/sisal biocomposites may bein agricultural fields as structural systems with low-mechanical resistance requirements and where the biodegradability of the biocomposites can be considered an added value; and $46^{\circ} \mathrm{C}$ in order to simulate extremely warm service conditions. 
Thus, the aim of this work was to study the physico-chemical changes undergone in the materials during hydrothermal tests. The synergic effect of water and temperatures above the glass transition of PHBV on the water absorption capability and diffusion rate of PHBV/sisal biocomposites was evaluated.

\section{Experimental procedure}

\subsection{Materials and preparation of biocomposites}

Poly (hydroxybuterate-co-valerate) (PHBV) ENMAT Y1000P grade for injection moulding was purchased from Tianan Biologic (China). Sisal fibre was supplied by Thai Royal project (Thailand). Maleic anhydride (MA) 98\% of purity (Fluka) and dicumyl peroxide (DCP) 98\% of purity (Sigma Aldrich) were used as coupling agent and free radical initiator, respectively.

PHBV pellets and sisal fibre (length $0.5-1 \mathrm{~mm}$ ) were dried in an oven at $80{ }^{\circ} \mathrm{C}$ at least 12 hours and kept in zip bags to prevent the presence of moisture during processing. The fibre contents in the biocomposite were formulated as $10 \%, 20 \%$ and $30 \%$ by weight. In case of using coupling agent (CA), MA 2.5\% and DCP 0.3\% were added. All materials were mixed in aBrabender (Germany) internal mixerduring 5 minutes at $180{ }^{\circ} \mathrm{C}$ and 50 rpm of speed.

The compounded fibre/PHBV biocomposite was ground by means of a grinder. These granules were dried at $80{ }^{\circ} \mathrm{C}$ in the oven at least 12 hours before further compression moulding, in order to avoid the hydrolysis degradation by moisture during the thermal process. Squared $100 \mathrm{~mm}^{2}$ biocomposite sheets were fabricated by using a compression moulding (Fontijne Presses, Holland). The compress machine was operated under vacuum conditions, pressing force of $100 \mathrm{kN}$, temperature of $190{ }^{\circ} \mathrm{C}$ during 2 minutes. An integrated cooling system permitted the extraction of the biocomposites preventing further degradation. Finally, squared $20 \mathrm{~mm}^{2}$ specimens were prepared for further hydrothermal testing and analytical characterization. 


\subsection{Hydrothermal testing}

A normalised water absorption test reported in the ISO $62^{\mathrm{e}}$, method 1 [18] was adopted as hydrothermal environment, modifying the temperature specifications to the desired ageing conditions. Initially, the specimens were previously dried at $50{ }^{\circ} \mathrm{C}$ in a vacuum oven during $24 \mathrm{~h}$, and then kept in a desiccator at normalized lab conditions according to ISO 291 [19]. The samples were submerged into distilled water at three different temperatures: 26, 36 and $46{ }^{\circ} \mathrm{C}$ during $100 \mathrm{~h}$. After certain periods of time, the specimens were removed from water, gently wiped to get rid of surface moieties, then weighed and finally submerged back into water. The average content of absorbed water was calculated by quintuplicate by weigh difference.

\subsection{Analytical monitoring of the hydrothermal test}

\subsubsection{Fourier-Transform Infrared Spectroscopy (FTIR)}

The functional groups of PHBV biocomposites after hydrothermal ageing were monitored with a FTIR spectrometer Spectrum 2000 from Perkin Elmer (Waltham, MA) equipped with a golden gate attenuated total reflection (ATR) holder with a diamond FTIR crystal. Each spectrum was based on 16 scans with a resolution of $4 \mathrm{~cm}^{-1}$.

\subsubsection{Size exclusion chromatography (SEC)}

Molecular weight of PHBV and their composites were analysed by size exclusion chromatography (SEC). PHBV sample was dissolved in chloroform (Fluka, purity of $99 \%$ ) with a concentration of $3-5 \mathrm{mg} / \mathrm{ml}$ at $80^{\circ} \mathrm{C}$ for 2 hours. The sample solution was filtered for removal of contaminants and fibres before injecting the sample into the SEC column. The polymers were analysed with a Verotech PL-GPC 50 Plus system equipped with a PL-RI Detector and two PLgelAutosampler for PL-GPC 50 Plus, in which chloroform was used as mobile phase $\left(1 \mathrm{ml} / \mathrm{min}, 30^{\circ} \mathrm{C}\right)$. The calibration was created using polystyrene standards with a narrow molecular weight distribution. Corrections for the flow rate fluctuations were made using toluene as an internal standard. 


\subsubsection{Differential Scanning Calorimetry (DSC)}

DSC analyses were carried out by a Mettler Toledo DSC 822 instrument (Columbus, OH) calibrated with indium and zinc standards. $\sim 5 \mathrm{mg}$ of pellets were placed in $40 \mathrm{~mL}$ aluminum pans, which were sealed and pierced to allow the $\mathrm{N}_{2}$ gas flow $\left(50 \mathrm{~mL} \cdot \mathrm{min}^{-1}\right)$. A $10{ }^{\circ} \mathrm{C} \cdot \mathrm{min}^{-1}$ heating/cooling/heating program was used in the temperature range between $-40{ }^{\circ} \mathrm{C}$ and $200{ }^{\circ} \mathrm{C}$. DSC analyses were performed with the aid of the software STAR $^{\text {e }} 9.10$ from Mettler-Toledo. The specimens were characterized at least by triplicate and the averages of temperatures and enthalpies were taken as representative values.

\subsubsection{Scanning Electron Microscopy (SEM)}

The surface morphology of the specimens was analysed by means of a Hitachi S-4800 Field Emission Scanning Electron Microscope (Tokyo, Japan). The samples were cut to small pieces and dried at $70^{\circ} \mathrm{C}$ for $24 \mathrm{~h}$ and then kept in desiccator for $48 \mathrm{~h}$ before SEM sample preparation. The pieces were mounted on metal studs and sputter-coated with a 2 nm gold layer using a Cressington208HR, high resolution sputter coater (Watford, UK), equipped with a Cressington thickness monitor controller.

\section{Results and discussion.}

\subsection{The water absorption behavior of PHBV/sisal biocomposites}

Figure 1 shows the percentage of water absorption $M_{t}$ for neat PHBV and its corresponding PHBV/sisal biocomposites with and without coupling agent, at the three hydrothermal test temperatures $T_{H}$ chosen for the study. A one-step mass-uptake process with a characteristic rapid water absorption followed by an asymptotic curve until saturation was observed for all samples.

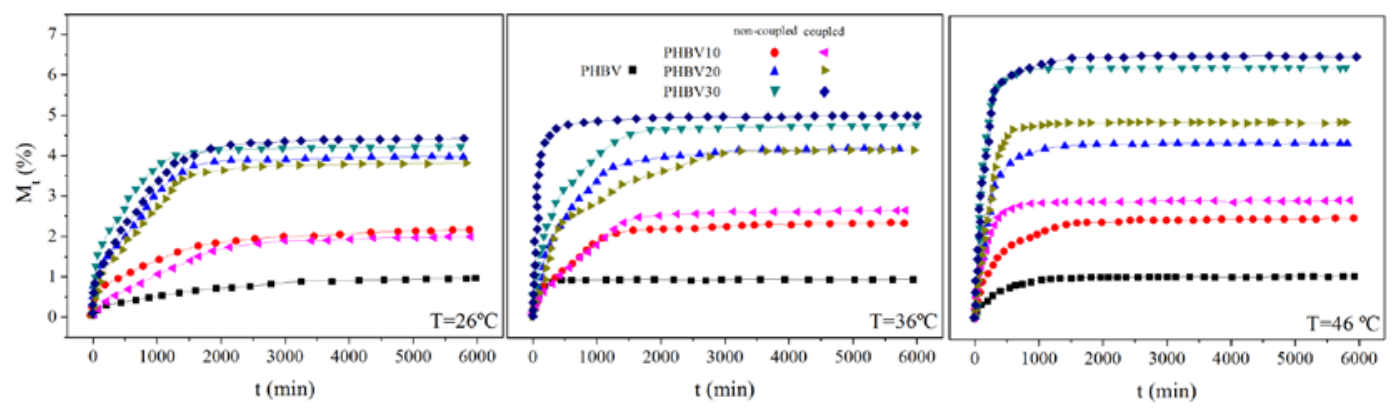

Figure 1. Water absorption profiles for the PHBV/sisal biocomposites at $26^{\circ} \mathrm{C}$ (a), $36^{\circ} \mathrm{C}$ (b) and 46 ${ }^{\circ} \mathrm{C}$ (c). 
The discussion of results should take into account both the influence of intrinsic factors, such as the relative amount of fibre in the biocomposite (\%f), and use of maleic anhydride as coupling agent $(C A)$, and extrinsic factors, such as the hydrothermal testing temperature of analysis $T_{H}$. At a first sight to the plots, one may interpret that, as expected, the saturation of the curves was achieved at higher values, the higher both the amount of fibre and the hydrothermal test temperatures were. As well, the slopes of the growing initial component of the curves were steeper in the same fashion, which may be a hint for interpreting faster water diffusion rate. Figure $\mathbf{1}$ also remarks that the higher the temperature of the tests was, the larger the differences among water absorption profiles were.

The performance of PHBV/sisal biocomposites facing the hydrothermal test was then approached by focusing the analysis on the water saturation capability $M_{S}(\%)$ and the water diffusion coefficient $D\left(\mathrm{~m}^{2} \mathrm{~s}^{-1}\right)$ [20]. From the plots, $M_{S}$ can be obtained as the average of the experimental points at the horizontal asymptotic section. $D$ is usually obtained by using Eq. (1) at short $t$ where $L$ is the thickness of the sample, which is twice the length of the pathway of diffusion, from the slope of the linear fitting of $M_{t} \mathrm{vs} \mathrm{t}^{1 / 2} \mathrm{~L}^{-1}$, as explained in a previous report [11]. The values of the saturation masses $M_{S}$ and the diffusion coefficients $D$ are gathered in Table 1 and Table 2, respectively.

$$
\frac{M_{t}}{M_{S}} \approx \frac{8}{\pi^{\frac{1}{2}}} \cdot\left(\frac{D \cdot t}{L^{2}}\right)^{\frac{1}{2}}
$$

Table 1. Saturation masses of PHBV/sisal biocomposites after hydrothermal tests at 26, 36 and 46 ${ }^{\circ} \mathrm{C}$.

\begin{tabular}{|c|c|c|c|c|c|c|}
\hline & \multicolumn{6}{|c|}{ Hydrothermal test temperature $\left({ }^{\circ} \mathrm{C}\right)$} \\
\hline & \multicolumn{2}{|c|}{26} & \multicolumn{2}{|c|}{36} & \multicolumn{2}{|c|}{46} \\
\hline 0 & \multicolumn{2}{|c|}{$0.950 \pm 0.051$} & \multicolumn{2}{|c|}{$0.984 \pm 0.048$} & \multicolumn{2}{|c|}{$1.065 \pm 0.046$} \\
\hline \multirow{2}{*}{$\begin{array}{c}\text { Content of fibre } \\
\text { (\%f) }\end{array}$} & \multicolumn{6}{|c|}{ Use of coupling agent } \\
\hline & NO & YES & NO & YES & NO & YES \\
\hline 10 & $2.169 \pm 0.108$ & $1.996 \pm 0.101$ & $2.334 \pm 0.119$ & $2.646 \pm 0.132$ & $2.499 \pm 0.123$ & $2.942 \pm 0.147$ \\
\hline 20 & $3.971 \pm 0.193$ & $3.798 \pm 0.190$ & $4.182 \pm 0.206$ & $4.144 \pm 0.207$ & $4.350 \pm 0.214$ & $4.871 \pm 0.243$ \\
\hline 30 & $4.216 \pm 0.208$ & $4.400 \pm 0.198$ & $4.733 \pm 0.237$ & $4.991 \pm 0.250$ & $6.227 \pm 0.311$ & $6.488 \pm 0.324$ \\
\hline
\end{tabular}


Table 2.Water diffusion rate of PHBV/sisal biocomposites after hydrothermal tests at 26, 36 and 46 ${ }^{\circ} \mathrm{C}$.

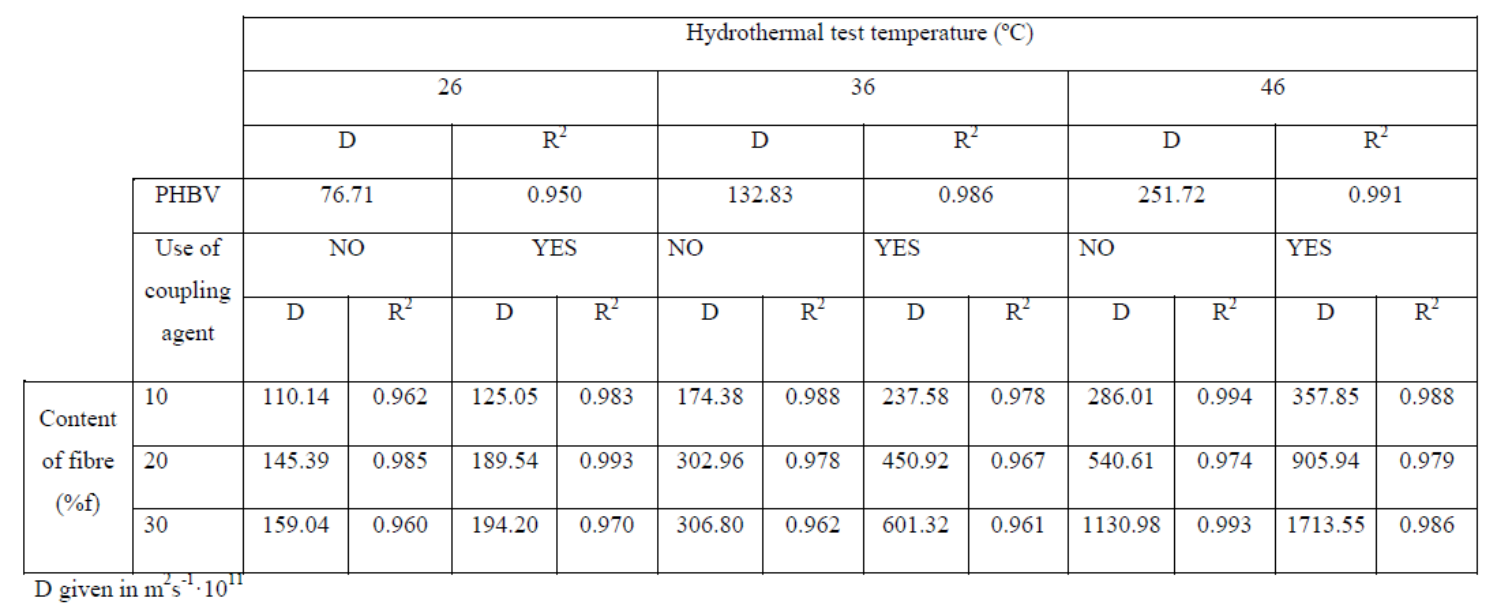

These results showed a general increase of $M_{S}$ and $D$ of PHBV/sisal biocomposites for higher fibre content, use of coupling agent and temperature of tests. However, literature shows other behaviours, depending on factors such as the nature of the filler or the macromolecular structure of the polymer matrix. Regarding the filler, the use of nanohydroxyapatite on PHBV also showed an increase of $M_{S}$ with an increasing content of filler, whereas the $D$ was reduced, since the filler acted as a blocker of the water diffusion paths in the biocomposite [16]. Concerning the structure of the polymer matrix, studies with PLA and subsequent recyclates showed the formation of a crystalline fraction along the water absorption process which reduced both $M_{S}$ and $D$, even when the hydrothermal testing temperatures increased [11].

\subsection{A statistical factorial analysis to quantify the relative influence of fibre, coupling agent and temperature on the water absorption performance}

In order to quantify the influence of the factors, i.e., fibre content, coupling agent and hydrothermal testing temperature, on the water absorption performance of PHBV/sisal biocomposites, a statistical factorial analysis (SFA) was applied. As was reported in previous studies [21-22] a SFA involves the study of the influence of multiple factors on the experimental outcome, i.e. the response can be either qualitative -i.e. categorical variable, such as the use or not of coupling agent- or quantitative -based on discrete values of a quantifiable variable, such as the relative amount of fibre in the biocomposite or the hydrothermal testing temperature-. 
Each factor must have two or more experimental settings or levels, so that the effect of change in a level can be assessed on the response. Any combination of factors and levels corresponds to a run in practical experimentation. The factors under study were the content of fibre $(\% f)$, use of coupling agent $(C A)$ and the hydrothermal testing temperature $\left(T_{H}\right)$; whereas the water absorption capability $\left(M_{S}\right)$ and water diffusion coefficient $(D)$ were considered as Effects in the SFA. Table 3 shows the summary of factor and levels considered in the discussion.

Table 3. Summary of factors, levels and effects of the statistical factorial analysis performed in this study.

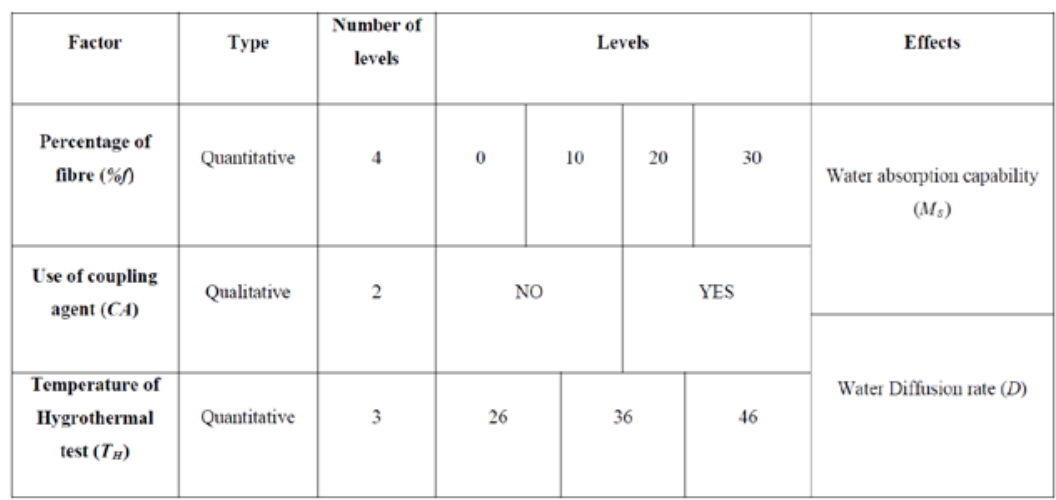

Figure 2 shows the so-called main-effects plot [22]which shows the direct effect of each factor on the statistical means of $M_{S}$ (a) and $D$ (b), evaluated along the different considered experimental settings of $\% f, C A$ and $T_{H}$.
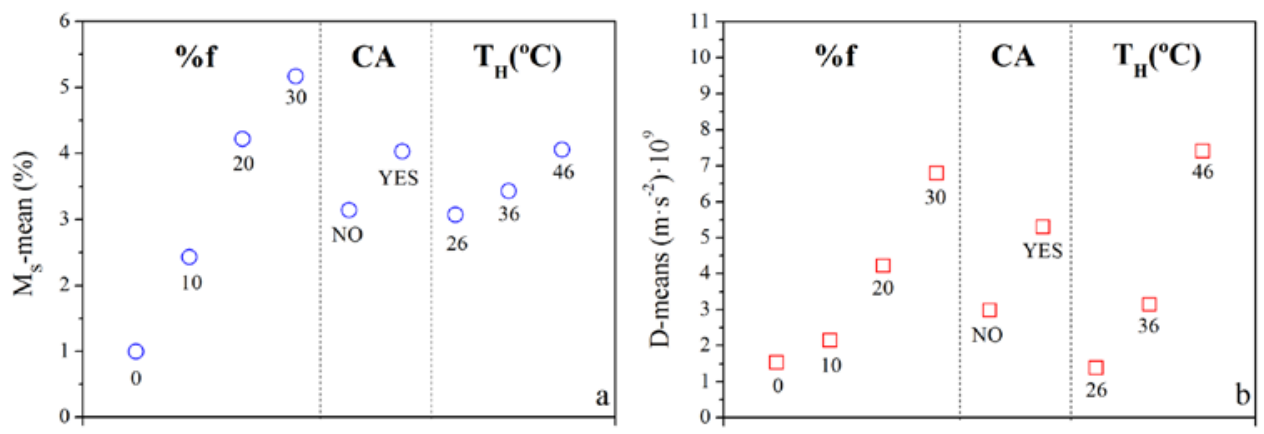

Figure 2. Main-effects plot of water absorption capability $M_{S}($ a) and water diffusion rate $D(b)$ in terms of percentage of fibre (\%f), use of coupling agent (CA) and hydrothermal testing temperatures $\left(T_{H}\right)$ 
The percentage of fibre \%f was significantly influent for $M_{S}$, while the hydrothermal testing temperature $T_{H}$ was determinant in the case of $D$, since the slopes were larger. These findings were quantified, by means of Eq. 2 [21] :

$$
E\left(\left.\Delta L\right|_{F}\right)(\%)=\left.\frac{\overline{E(L)-E\left(L_{\mathrm{REF}}\right)}}{E\left(L_{\mathrm{REF}}\right)}\right|_{F} \times 100(2)
$$

, where $E$ means the effect $\left(M_{S}\right.$ or $\left.D\right), \mathrm{F}$ the factor ( $\% f, C A$ or $\left.T_{H}\right)$ and $L$ the level or experimental setting of analysis. The selection of the reference level $\left(L_{R E F}\right)$ for each factor is arbitrary and for convenience the $a$ priori less affected state was chosen. The choices were stated as follows: 0 for the factor $\% f$, NO for the factor $C A$ and $26^{\circ} \mathrm{C}$ for the factor $T_{H}$. Figure 3 shows the relative variations of $M_{S}$ and $D$ due to the influence of each factor.

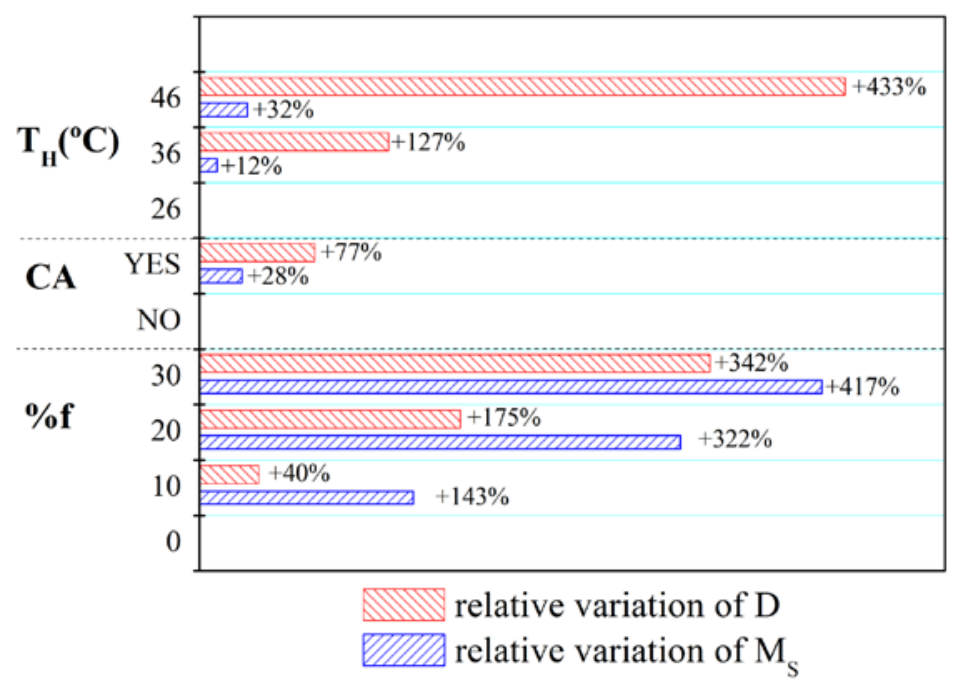

Figure 3. Relative variations of MS and D from a reference state ( 0 for the factor $\% f$, NO for the factor $C A$ and $26^{\circ} \mathrm{C}$ for the factor $T_{H}$ )

It was observed that $M_{S}$ was more affected than $D$ in terms of percentage of fibre, which can be attributed to the extra absorption of water promoted by the presence of fibres. On the contrary, the effect of the coupling agent is more pronounced for the case of the $D$, since it increased $\sim 77 \%$, while $M_{S}$ only increased $\sim 28 \%$. The effect of the temperature was clearly more significant for $D$. In fact, D increased a $\sim 127 \%$ when $T_{H}$ was augmented $10^{\circ} \mathrm{C}$ from $26^{\circ} \mathrm{C}$ to $36^{\circ} \mathrm{C}$. Even more, this increase was bigger when the gap in temperature was risen $20^{\circ} \mathrm{C}$, up to $46^{\circ} \mathrm{C}$, registering a $\sim 433 \%$ of increase in $D$. 
More information can be drawn from the study of the synergic influence of a combination of two factors. In this sense, the so-called interaction-effects plots (IEP) are useful for the study of interactions between factors by means of the comparison of the relative strength of the effects across factors. An interaction between factors occurs when the change in response in terms of levels $L$ from the low- $L$ to the high- $L$ of one factoris not the same as the change in response at the same two $L$ of a second factor. That is, the effect of one factor is dependent upon a second factor. Figure 4 shows the IEP for $M_{S}$ (sub-plots a, b, c) and $D$ (subplots d,e,f) in terms of dual combinations between $T_{H}, \% f$ and $C A$.

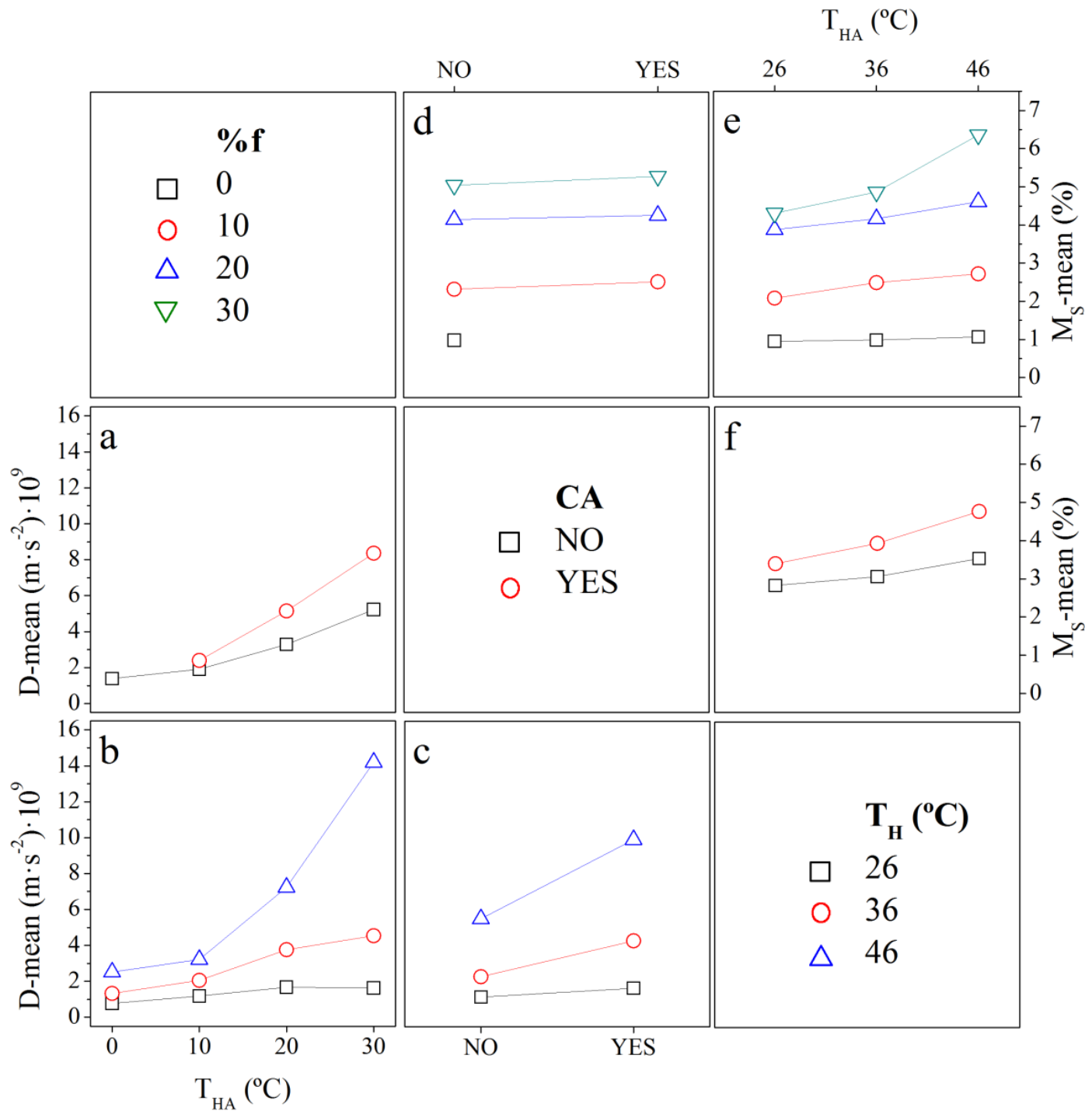

Figure 4. Interaction-effects plot of water absorption capability $M_{s}(a)$ and water diffusion rate $D$ (b) in terms of percentage of fibre (\%f), use of coupling agent (CA) and hydrothermal testing temperatures $\left(T_{H}\right)$ 
The inspection of these plots offered different discussions:

(i) when it comes to the combined effect of percentage of fibre and use of coupling agent (Figs 4a and 4d), on may note that there is no practically influence of the addition of $C A$ in terms of $M_{s}$, for any of the different $\% f$ formulations, while for the case of the $D$, it was positively affected by the use of CA, being the difference of $D$ improved the higher the more amount of fibre was present in the biocomposite.

(ii) considering the combined influence of percentage of fibre and temperature of hydrothermal testing (Figs $4 \mathrm{~b}$ and 4e), a direct effect was observed for both $M_{S}$ and $D$ values, being particularly remarkable the increase of $D$ experienced at $46^{\circ} \mathrm{C}$ for $\% f \geq 20 \%$. On the other hand, also the increases of $M_{S}$ with temperature $T_{H}$ were more pronounced for biocomposites the higher the $\% f$ content was.

(iii) finally, the influence of the $C A$ with $T_{H}$ was also positive for both $M_{S}$ and $D$, as can be seen in Figs 4c and 4f, due to the role of the new chemical bonds imposed between matrix and fibres, proactive in the performance of the biocomposites in terms of water absorption.

\subsection{The influence of the hydrothermal test on the chemical structure}

Fourier-Transform Infrared (FT-IR) Spectroscopy was used to evaluate the influence of the hydrothermal tests on the chemical structure of PHBV/sisal biocomposites after saturation. As example, Figure 5 shows a comparison of FT-IR spectra of PHBV and PHBV reinforced with $10 \%$ and $30 \%$ of sisal before and after hydrothermal testing at 36 ${ }^{\circ} \mathrm{C}$ during 100h. The rest of materials showed similar FT-IR spectra regardless the biocomposite composition and hydrothermal test temperature. The zoomed spectra of the stretching vibration of the carbonyl group $\left(\sim 1719 \mathrm{~cm}^{-1}\right)$ and the hydroxyl group (3306 $\mathrm{cm}^{-1}$ ) were chosen for discussion [23,24]. As can be seen, there was a generalised reduction of the intensity of the carbonyl peak, which might be a hint of chemical degradation. However, the hydroxyl area does not present remarkable variations, which may indicate that after $100 \mathrm{~h}$ at any of the temperatures, the chemical structure of the matrix in the biocomposites at the surface level was not significantly affected by hydrolysis. 


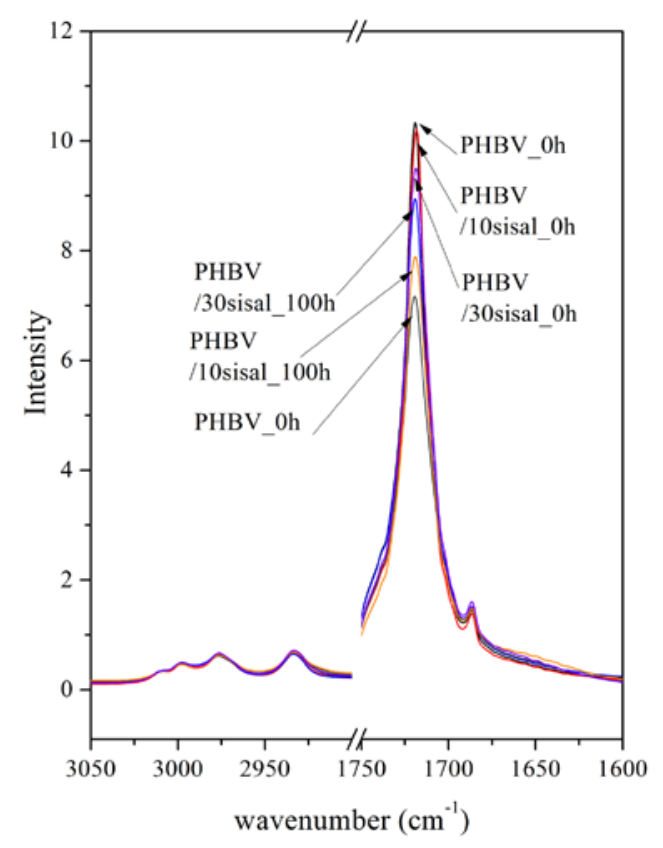

Figure5. Comparison of FT-IR spectra of PHBV and PHBV reinforced with $10 \%$ and $30 \%$ of sisal before and after hydrothermal testing at $36^{\circ} \mathrm{C}$ during $100 \mathrm{~h}$. The areas of the stretching vibration of the carbonyl group $\left(\sim 1719 \mathrm{~cm}^{-1}\right)$ and the hydroxyl group $\left(3306 \mathrm{~cm}^{-1}\right)$ are highlighted.

In order to quantify the extent of degradation, the carbonyl intensity index as derived from a ratio of the intensity heights at $\mathrm{C}=\mathrm{O}\left(1719 \mathrm{~cm}^{-1}\right) / \mathrm{CH}_{3}\left(1379 \mathrm{~cm}^{-1}\right)$ was quantified, before and after hydrothermal test for all materials and all temperatures. The results are shown in Figure 6. As expected, a general decrease of carbonyl index was found, being more accused for higher hydrothermal test temperatures $T_{H}$, although somehow buffered for PHBV/sisal biocomposites with higher amounts of fibre. The use of coupling agent did not remarkably modify this behaviour. In any case, the variations among hydrothermally tested materials were lower than $5 \%$, so one may discuss that once submerged the materials into water, the extent of chemical degradation is similar for all biocomposites, and practically not dependent on temperature. 


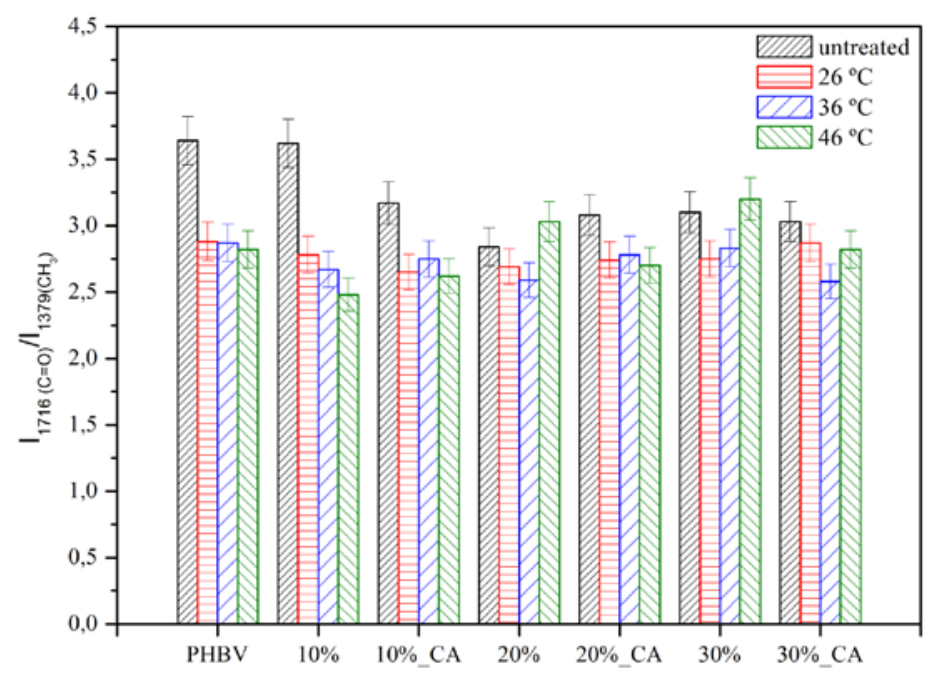

Figure6. Carbonyl index for PHBV and PHBV/sisal biocomposites, both untreated and subjected to hydrothermal testing at 26,36 and $46{ }^{\circ} \mathrm{C}$ during $100 \mathrm{~h}$.

The molar mass was a more significant parameter to monitor the impact of the degradation medium in thebulk PHBV/sisal biocomposites. Figure 7 shows the molar mass in number $M_{n}$ for untreated specimens compared with those extracted at 40 and 100 $\mathrm{h}$ of hydrothermal exposition. In general terms, different observations were made: (i) the incorporation of fibres buffered the initial reduction of $M_{n}$ observed for virgin PHBV submerged into the water,although reduced the initial molar mass of the biocomposites (ii) the higher the amount of fibres, the lower the differences among $M_{n}$ of biocomposites at different temperatures, in accordance to FT-IR results; (iii) the addition of coupling agent resulted in a reduction of the $M_{n}$ in all cases, regardless the amount of fibre in the biocomposite; (iv) most of the degradation occurred during the first $40 \mathrm{~h}$ of hydrothermal exposition, being practically irrelevant the variation of $M_{n}$ during the rest of the experiment, regardless the amount of fibre and the temperature of the hydrothermal test. 


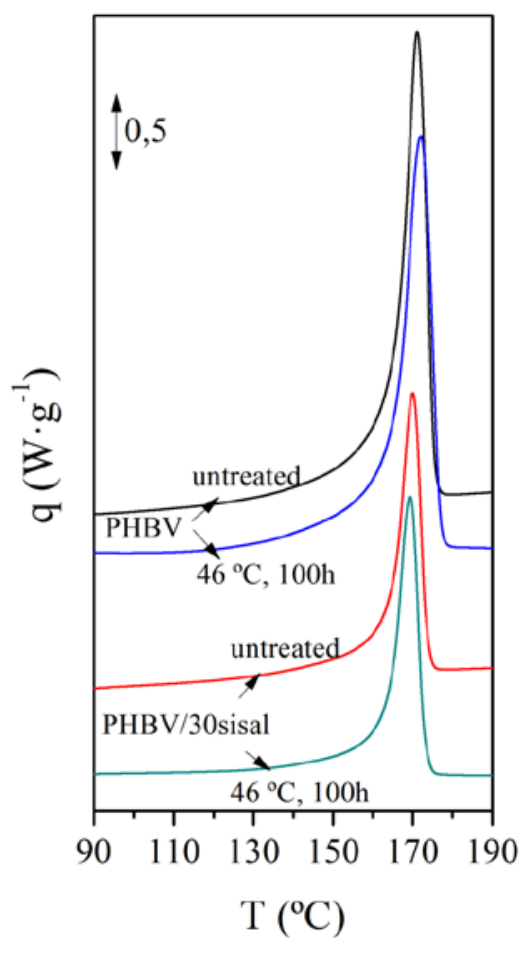

Figure 7. Evolution of the molar mass Mn for PHBV and PHBV/sisal biocomposites, both untreated and subjected to hydrothermal testing at 26, 36 and $46^{\circ} \mathrm{C}$ during 40 and $100 \mathrm{~h}$.

\subsection{Effect of hydrothermal test on thermal properties}

Differential scanning calorimetry (DSC) has been previously shown to be an interesting technique to monitor the morphological changes and thermal properties of polymer samples subjected to the different degradingambients [11, 23-26]. However, the DSC spectra of the PHBV biocomposites evidenced slight variations only for the change from neat biocomposites to those subjected to any of the three hydrothermal test temperatures, as shown in Figure 8for the limiting cases, that is, PHBV and PHBV reinforced with 30\% of sisal, both untreated and subjected to the hydrothermal test of $46^{\circ} \mathrm{C}$ during $100 \mathrm{~h}$. All samples, which showed similar profiles, regardless the fibre content, use of coupling agent or the temperature of the hydrothermal testing temperature, lie between these DSC spectra. 


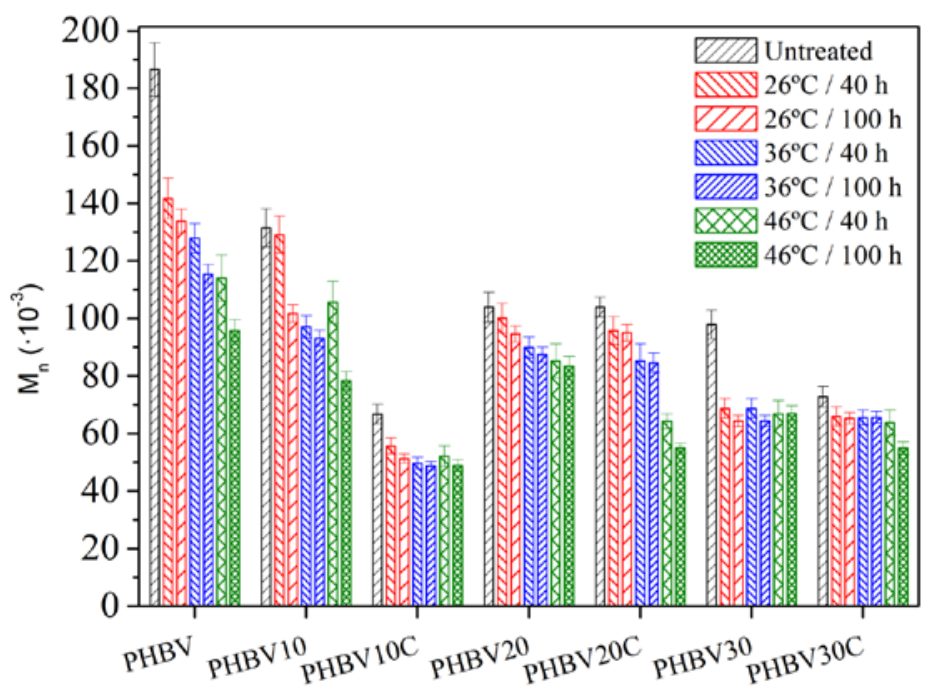

Figure 8.DSC re-heating spectra of PHBV and PHBV reinforced with $30 \%$ of sisal, both untreated and subjected to the hydrothermal test of $46^{\circ} \mathrm{C}$ during $100 \mathrm{~h}$

Table 4 and Table 5 respectively show the peak temperatures and enthalpies corresponding to the exothermic crystallization upon cooling and endothermic melting upon re-heating, for the untreated PHBV biocomposites and those subjected to the different hydrothermal test conditions. 
Table 4.Crystallization temperatures and enthalpies of all PHBV biocomposites, monitored during all hydrothermal tests.

\begin{tabular}{|c|c|c|c|c|c|c|c|c|c|c|c|c|c|c|}
\hline & & & \multicolumn{12}{|c|}{ Crystallization curve } \\
\hline & & & \multicolumn{12}{|c|}{ Hydrothermal test temperature $\left({ }^{\circ} \mathrm{C}\right)$} \\
\hline & & & \multicolumn{4}{|c|}{26} & \multicolumn{4}{|c|}{36} & \multicolumn{4}{|c|}{46} \\
\hline & & $\begin{array}{l}t_{\mathrm{mu}}( \\
\text { h) }\end{array}$ & \multicolumn{2}{|c|}{$\mathrm{T}_{c}\left({ }^{\circ} \mathrm{C}\right)$} & \multicolumn{2}{|c|}{$\Delta \mathbf{h}_{c}\left(\mathbf{J}^{-1}\right)$} & \multicolumn{2}{|c|}{$\mathrm{T}_{c}\left({ }^{\circ} \mathrm{C}\right)$} & \multicolumn{2}{|c|}{$\Delta \mathbf{h}_{c}\left(\mathrm{~J} \mathbf{g}^{-1}\right)$} & \multicolumn{2}{|c|}{$\mathrm{T}_{c}\left({ }^{\circ} \mathrm{C}\right)$} & \multicolumn{2}{|c|}{$\Delta \mathbf{h}_{c}\left(\mathrm{Jg}^{-1}\right)$} \\
\hline \multirow{4}{*}{\multicolumn{2}{|c|}{ PHBV }} & 0 & \multicolumn{6}{|c|}{$\operatorname{Tc}\left({ }^{\circ} \mathrm{C}\right)=123.5 \pm 0.1$} & \multicolumn{4}{|c|}{$\Delta h_{C}\left(k^{\prime} g^{-1}\right)=-101.22 \pm 3.72$} & & \\
\hline & & 6 & \multicolumn{2}{|c|}{$119.3 \pm 0.1$} & \multicolumn{2}{|c|}{$-79.81 \pm 0.20$} & \multicolumn{2}{|c|}{$121.5 \pm 0.1$} & \multicolumn{2}{|c|}{$-74.94=0.30$} & \multicolumn{2}{|c|}{$121.3=0.3$} & \multicolumn{2}{|c|}{-93.58} \\
\hline & & 28 & \multicolumn{2}{|c|}{$121.8 \pm 0.1$} & \multicolumn{2}{|c|}{$-75.49 \div 3.18$} & \multicolumn{2}{|c|}{$120.9 \pm 0.1$} & \multicolumn{2}{|c|}{$-78.27 \pm 4.41$} & \multicolumn{2}{|c|}{$121.4=0.1$} & \multicolumn{2}{|c|}{$-90.89 \pm 0.49$} \\
\hline & & 100 & \multicolumn{2}{|c|}{$119.5 \pm 0.4$} & \multicolumn{2}{|c|}{$-78.83 \pm 2.49$} & \multicolumn{2}{|c|}{$120.6 \pm 0.5$} & -77.28 & $=1.22$ & & $3=0.3$ & -92.5 & $7 \pm 0.27$ \\
\hline & Use of C & & & & & ES & & 10 & $\mathbf{Y}$ & & & $\mathbf{0}$ & & ES \\
\hline & & $t_{\mathrm{BA}}(\mathrm{h})$ & $\mathrm{T}_{\mathrm{c}}\left({ }^{\circ} \mathrm{C}\right)$ & $\begin{array}{c}\Delta \mathbf{b h}_{\mathrm{c}}(\mathbf{J} \mathbf{g} \\
5 \\
5\end{array}$ & $\mathbf{T}_{c}\left({ }^{\circ} \mathrm{C}\right)$ & $\begin{array}{c}\Delta \mathbf{h}_{\mathrm{C}}(\mathbf{J} \boldsymbol{g} \\
\left.{ }_{1}\right)\end{array}$ & $\left.\mathrm{T}_{\mathrm{C}}{ }^{\circ} \mathrm{C}\right)$ & $\begin{array}{c}\Delta \mathbf{b h}_{\mathrm{C}}(\mathbf{J} \mathbf{g} \\
\mathrm{j}\end{array}$ & $\left.\mathrm{T}_{\mathrm{c}}{ }^{\circ}{ }^{\circ} \mathrm{C}\right)$ & $\begin{array}{c}\Delta \mathbf{h}_{c}(\mathbf{J} \mathbf{g} \\
1)\end{array}$ & $\mathrm{T}_{c}{ }^{\left({ }^{\circ} \mathrm{C}\right)}$ & $\begin{array}{c}\Delta \mathbf{h h}_{\mathrm{C}}(\mathrm{Jg} \mathbf{g} \\
\mathrm{j}\end{array}$ & $\left.\mathrm{T}_{\mathrm{C}}{ }^{\circ}{ }^{\circ} \mathrm{C}\right)$ & $\begin{array}{c}\Delta h_{\mathrm{c}}(\mathrm{Jg} \\
\mathrm{j}\end{array}$ \\
\hline & & 0 & & $(\mathrm{NO}) \mathrm{T}_{\mathrm{C}} \mathrm{C}$ & $=124.2 \pm 0$. & $\Delta \mathrm{h}_{\mathrm{c}}\left(\mathrm{J} \mathrm{g}^{\prime}\right)=$ & $-86.86 \pm 2.53$ & & & YES) $T_{C}\left({ }^{\circ} \mathrm{C}\right)$ & $=122.9=0.4$ & $\Delta \mathrm{h}_{\mathrm{c}}\left(\mathrm{J} \mathrm{g}^{\prime}\right)=$ & $81.68=2.42$ & \\
\hline & & 6 & $\begin{array}{c}120.0 \pm 0 . \\
1\end{array}$ & $\begin{array}{c}-\overline{-} \\
68.01 \pm 1 . \\
28\end{array}$ & $\begin{array}{c}119.5 \pm 0 \\
.1\end{array}$ & $\begin{array}{c}73.20=0 . \\
60\end{array}$ & $\begin{array}{c}120.0=0 \\
.2\end{array}$ & $\begin{array}{c}- \\
70.51=3.6\end{array}$ & $\begin{array}{c}119.35 \pm 0 . \\
58\end{array}$ & $\begin{array}{c}-\overline{-} \\
71.49=0 . \\
94\end{array}$ & $\begin{array}{c}120.6 \pm 0 . \\
3\end{array}$ & $\begin{array}{c}-\overline{60}=1 . \\
28\end{array}$ & $\begin{array}{c}119.4 \pm 0 \\
5\end{array}$ & $\begin{array}{c}- \\
70.13 \pm 1 . \\
3\end{array}$ \\
\hline & 10 & 28 & $\begin{array}{c}120.4 \pm 0 . \\
1\end{array}$ & $\begin{array}{c}- \\
70.2 \pm 0.9 \\
7\end{array}$ & $\begin{array}{c}118.9 \pm 0 \\
.1\end{array}$ & $\begin{array}{c}-\overline{2}=1 . \\
81\end{array}$ & $\begin{array}{c}120.1=0 \\
.1\end{array}$ & $\begin{array}{c}- \\
72.56=1.9 \\
8\end{array}$ & $119.5 \pm 0.1$ & $\begin{array}{c}\overline{-} \\
71.71=4 . \\
01\end{array}$ & $\begin{array}{c}121.3 \pm 0 \\
1\end{array}$ & $\begin{array}{c}\overline{-} \\
79.00=2 . \\
26\end{array}$ & $\begin{array}{c}120.0 \pm 0 \\
3\end{array}$ & $\begin{array}{c}-\overline{-} \\
69.32 \pm 1 . \\
61\end{array}$ \\
\hline & & 100 & $\begin{array}{c}120.2 \pm 0 \\
3\end{array}$ & $\begin{array}{c}- \\
71.13 \pm 0 . \\
47\end{array}$ & $\begin{array}{c}119.4 \pm 0 \\
.1\end{array}$ & $\begin{array}{c}-\overline{-} \\
64.70=4 . \\
51\end{array}$ & $\begin{array}{c}119.8=0 \\
.2\end{array}$ & $\begin{array}{c}- \\
73.74=0.2 \\
2\end{array}$ & $119.8 \pm 0.1$ & $\begin{array}{c}-\overline{2} \\
74.28=2 . \\
07\end{array}$ & $\begin{array}{c}121.2 \pm 0 . \\
1\end{array}$ & $\begin{array}{c}-\overline{-} \\
81.58 \pm 0 . \\
55\end{array}$ & $\begin{array}{c}119.2 \pm 0 \\
.1\end{array}$ & $\begin{array}{c}69.22 \pm 4 \\
37\end{array}$ \\
\hline & & 0 & & (NO) $T_{c} C^{\circ}$ & $=123.6 \pm 0$. & $\Delta \mathrm{h}_{\mathrm{c}}\left(\mathrm{J} \mathrm{g}^{\prime}\right)=$ & $-61.65 \pm 1.23$ & & & (YES) $\mathrm{T}_{\mathrm{c}}{ }^{\circ} \mathrm{C}$ & $=123.5 \pm 0.1$ & $\Delta \mathrm{h}_{\mathrm{c}}\left(\mathrm{Jg} \mathrm{g}^{\mathrm{T}}\right)=$ & $63.69 \pm 3.7$ & \\
\hline Conte & & 6 & $\begin{array}{c}118.7 \pm 0 . \\
1\end{array}$ & $\begin{array}{c}-\overline{-} \\
281 \pm 0 .\end{array}$ & $\begin{array}{c}119.2 \pm 0 \\
.1\end{array}$ & $\begin{array}{c}-.88 \div 3 \\
57\end{array}$ & $\begin{array}{c}118.3=0 \\
.2\end{array}$ & $\begin{array}{c}- \\
61.92 \neq 1.7 \\
8\end{array}$ & $\begin{array}{c}118.78 \pm 0 . \\
34\end{array}$ & $\begin{array}{c}- \\
59.51=2.3 \\
9\end{array}$ & $\begin{array}{c}119.7 \pm 0 \\
.2\end{array}$ & $\begin{array}{c}57.08+1 . \\
32\end{array}$ & $\begin{array}{c}119.1 \pm 0 \\
2\end{array}$ & $\begin{array}{c}- \\
60.18 \pm 2 \\
17\end{array}$ \\
\hline $\begin{array}{l}\text { nt of } \\
\text { fibre } \\
(\%)\end{array}$ & 20 & 28 & $\begin{array}{c}119.2 \pm 0 \\
1\end{array}$ & $\begin{array}{c}- \\
62.34 \pm 2 . \\
39\end{array}$ & $\begin{array}{c}119.0=0 \\
.2\end{array}$ & $\begin{array}{c}64.33 \pm 4 . \\
32\end{array}$ & $119=0.2$ & $\begin{array}{c}- \\
60.195=1 \\
53\end{array}$ & $119.1=0.1$ & $\begin{array}{c}- \\
62.75=0.6 \\
3\end{array}$ & $\begin{array}{c}119.0=0 \\
.1\end{array}$ & $\begin{array}{c}-\overline{-} \\
59.84 \pm 0 . \\
15\end{array}$ & $\begin{array}{c}119.0=0 \\
2\end{array}$ & $\begin{array}{c}- \\
58.21 \pm 7 \\
16\end{array}$ \\
\hline & & 100 & $\begin{array}{c}1189 \pm 0 . \\
2\end{array}$ & $\begin{array}{c}- \\
22.29=4 .\end{array}$ & $\begin{array}{c}119.0=0 \\
.2\end{array}$ & $\underset{66}{62.97 \pm 0 .}$ & $\begin{array}{c}118.5 \neq 0 \\
.4\end{array}$ & $\begin{array}{c}- \\
62.81=2.4 \\
1\end{array}$ & $118.9 \pm 0.1$ & $\begin{array}{c}- \\
61.04=13 . \\
06\end{array}$ & $\begin{array}{c}119.9 \neq 0 \\
.1\end{array}$ & $\begin{array}{c}-\overline{-} \\
41.27 \pm 4 .\end{array}$ & $\begin{array}{c}119.2 \pm 0 \\
.1\end{array}$ & $\begin{array}{c}58.78 \pm 0 . \\
02\end{array}$ \\
\hline & & 0 & & (NO) $T_{c}{ }^{2}$ & $=122.42=0$ & $1 \Delta \mathrm{b}_{\mathrm{c}}\left(\mathrm{J} \mathrm{g}^{\mathrm{l}}\right)^{2}=$ & $-62.70=1.2$ & & & (YES) $\mathrm{T}_{\mathrm{c}}{ }^{\circ} \mathrm{C}$ & $=122.1 \pm 0.1$ & $\Delta \mathrm{b}_{\mathrm{c}}\left(\mathrm{J} \mathrm{g}^{\mathrm{l}}\right)=$ & $63.69 \pm 3.7$ & \\
\hline & & 6 & $\begin{array}{c}118.6 \pm 0 . \\
1\end{array}$ & $\begin{array}{c}- \\
55.30 \pm 3 . \\
69\end{array}$ & $\begin{array}{c}117.7 \pm 0 \\
.5\end{array}$ & $\begin{array}{c}-\overline{-} \\
56.15=6 . \\
38\end{array}$ & $\begin{array}{c}118.0=0 \\
.1\end{array}$ & $\begin{array}{c}- \\
54.75=2.7 \\
1\end{array}$ & $\begin{array}{c}117.5 \pm 0.1 \\
97\end{array}$ & $\begin{array}{c}- \\
49.80=2.2 \\
8\end{array}$ & $\begin{array}{c}118.4=0 \\
.5\end{array}$ & -54.54 & $\begin{array}{c}118.2 \pm 0 \\
.1\end{array}$ & $\begin{array}{c}- \\
48.37 \pm 4 . \\
89\end{array}$ \\
\hline & 30 & 28 & $\begin{array}{c}118.3 \pm 0 \\
2\end{array}$ & $\begin{array}{c}- \\
56.74 \pm 3 . \\
38\end{array}$ & $\begin{array}{c}117.3 \pm 0 \\
.3\end{array}$ & $\begin{array}{c}54.12=1 \\
84\end{array}$ & $\begin{array}{c}117.1=0 \\
.3\end{array}$ & $-55.0 \pm 0.8$ & $118.2 \pm 0.5$ & $\begin{array}{c}- \\
56.36=7.5 \\
8\end{array}$ & $\begin{array}{c}118.1=0 \\
.1\end{array}$ & $\begin{array}{c}-\overline{8} .8 \pm 0 \\
64\end{array}$ & $\begin{array}{c}117.3 \pm 0 \\
.1\end{array}$ & $\begin{array}{c}- \\
47.70 \pm 2 \\
79\end{array}$ \\
\hline & & 100 & $\begin{array}{c}117.5 \pm 0 . \\
1\end{array}$ & $\begin{array}{c}- \\
51.17 \pm 0 . \\
39\end{array}$ & $\begin{array}{c}117.6 \pm 0 \\
.5\end{array}$ & $\begin{array}{c}52.14=1 \\
48\end{array}$ & $\begin{array}{c}118.2=0 \\
.6\end{array}$ & $\begin{array}{c}- \\
53.95=2.1 \\
8\end{array}$ & $117.5 \pm 0.4$ & $\begin{array}{c}- \\
58.21=0.4 \\
5\end{array}$ & $\begin{array}{c}117.9=0 \\
.3\end{array}$ & $\begin{array}{c}- \\
52.24 \pm 2 . \\
09\end{array}$ & $\begin{array}{c}118.2 \pm 0 \\
.1\end{array}$ & $\begin{array}{c}- \\
55.42 \pm 2 \\
32\end{array}$ \\
\hline
\end{tabular}


Table 5.Melting temperatures and enthalpies of all PHBV biocomposites, monitored during all hydrothermal tests.

\begin{tabular}{|c|c|c|c|c|c|c|c|c|c|c|c|c|c|c|}
\hline & & & & & & & & Meltinz: & curve & & & & & \\
\hline & & & & & & & & drothermal tes & temperature ( & & & & & \\
\hline & & & & & 6 & & & & & & & 4 & 6 & \\
\hline & & $t_{\mathrm{HA}}(\mathrm{h})$ & & ( $\left.{ }^{\circ} \mathrm{C}\right)$ & $\Delta \mathbf{h}_{M}$ & $\left.\mathrm{~J} \mathrm{~g}^{-1}\right)$ & & (C) & $\Delta \mathbf{h}_{\mathrm{M}}$ & $\left(\mathrm{J} \mathrm{g}^{-1}\right)$ & & ('C) & $\Delta \mathbf{h}_{\mathrm{M}}$ & $\left(\mathrm{Jg}^{-1}\right)$ \\
\hline & & 0 & & & & & $\mathrm{~T}_{M}\left({ }^{\circ} \mathrm{C}\right)=$ & $175.93 \pm 0.62 \Delta 3$ & $y\left(\mathrm{sJ} \mathrm{g}^{-1}\right)=10$ & $.51 \pm 6.56$ & & & & \\
\hline & & 6 & 174. & \pm 0.1 & 87.87 & 1.62 & & $5 \pm 0.4$ & 87.5 & \pm 0.78 & & $5 \pm 0.9$ & 99.1 & $2 \pm 0.65$ \\
\hline & & 28 & & 3.9 & 86.51 & 3.57 & & $2 \pm 0.3$ & 88.5 & \pm 4.58 & & $1 \pm 0.2$ & 100.1 & $4 \pm 1.88$ \\
\hline & & 100 & & $1 \pm 0.2$ & 88.55 & & & $5 \pm 0.8$ & 87.1 & \pm 1.32 & & $1 \pm 0.1$ & 102.0 & $2+2.38$ \\
\hline & se of $\mathrm{CA}$ & & & 0 & $\mathrm{Y}$ & & & so & & ES & & $\mathrm{O}$ & & ES \\
\hline & & $t_{\mathrm{HA}}(\mathbf{h})$ & $\mathrm{T}_{M}\left({ }^{\circ} \mathrm{C}\right)$ & $\underset{1}{\Delta \mathbf{h}_{M}}(\mathrm{Jg}$ & $\mathrm{T}_{\mathrm{M}}\left({ }^{\circ} \mathrm{C}\right)$ & $\underset{1}{\Delta \mathbf{h}_{M}}(\mathrm{Jg}$ & $\left.\mathrm{T}_{\mathrm{M}}{ }^{\circ} \mathrm{C}\right)$ & $\underset{1}{\Delta \mathbf{h}_{M}}(\mathrm{~J} \mathbf{g}$ & $\left.\mathrm{T}_{M}{ }^{\circ} \mathrm{C}\right)$ & $\underset{1}{\Delta \mathbf{h}_{M}(\mathrm{Jg}}$ & $\mathrm{T}_{\mathrm{M}}\left({ }^{\circ} \mathrm{C}\right)$ & $\underset{1}{\Delta \mathbf{h}_{M}(\mathrm{~J} g}$ & $\mathrm{T}_{\mathrm{M}}\left({ }^{\circ} \mathrm{C}\right)$ & $\underset{1}{\Delta \mathbf{h}_{M}}(\mathrm{Jg}$ \\
\hline \multirow{12}{*}{$\begin{array}{c}\text { Content } \\
\text { of fibre } \\
\text { (\%) }\end{array}$} & \multirow{4}{*}{10} & 0 & \multicolumn{6}{|c|}{ (NO) $\mathrm{T}_{\mathrm{M}}\left({ }^{\circ} \mathrm{C}\right)=176.1 \pm 0.2 \Delta \mathrm{h}_{\mathrm{M}}\left(\mathrm{J} \mathrm{g}^{-1}\right)=91.74 \pm 2.08$} & \multicolumn{6}{|c|}{ (YES) $\mathrm{T}_{\mathrm{M}}\left({ }^{\circ} \mathrm{C}\right)=174.2 \pm 0.7 \Delta \mathrm{h}_{\mathrm{M}}\left(\mathrm{Jg}^{-1}\right)=82.33 \pm 0.47$} \\
\hline & & 6 & $174.4 \pm 0.4$ & $75.91 \pm 1.95$ & $169.27 \pm 0.5$ & $81.46 \pm 0.70$ & $175.1 \pm 0.1$ & $79.93 \pm 3.91$ & $171.0 \pm 0.2$ & $78.97 \pm 1.31$ & $175.6 \pm 0.2$ & $79.69 \pm 0.67$ & $170.9 \pm 0.2$ & $78.09 \pm 1.12$ \\
\hline & & 28 & $174.6 \pm 0.3$ & $78.21 \pm 0.33$ & $171.1 \pm 1.1$ & $79.39 \pm 0.39$ & $173.8 \pm 0.1$ & $78.21 \pm 1.39$ & $171.2+1.4$ & $78.62 \pm 3.79$ & $174.4 \pm 0.7$ & $79.36 \pm 2.17$ & $171.0 \pm 0.1$ & $77.76 \pm 1.64$ \\
\hline & & 100 & $174.6 \pm 0.4$ & $78.89 \pm 0.51$ & $171.9 \pm 0.0$ & $75.68 \pm 2.88$ & $175.1 \pm 1.1$ & $80.94 \pm 1.11$ & $170.7 \pm 0.7$ & $81.15 \pm 1.68$ & $175.1 \pm 0.5$ & $81.98 \pm 0.61$ & $172.6 \pm 0.7$ & $78.06 \pm 2.07$ \\
\hline & \multirow{4}{*}{20} & 0 & \multicolumn{6}{|c|}{ (NO) $\mathrm{T}_{\mathrm{M}}\left({ }^{\circ} \mathrm{C}\right)=175.3 \pm 0.2 \Delta \mathrm{h}_{\mathrm{M}}\left(\mathrm{Jg}^{-1}\right)=69.86 \pm 4.13$} & \multicolumn{6}{|c|}{ (YES) $\mathrm{T}_{\mathrm{M}}\left({ }^{\circ} \mathrm{C}\right)=173.5 \pm 0.2 \Delta \mathrm{h}_{\mathrm{M}}\left(\mathrm{Jg}^{-1}\right)=73.75 \pm 1.59$} \\
\hline & & 6 & $170.9 \pm 1.1$ & $68.3 \pm 0.52$ & $174.2 \pm 0.7$ & $69.64 \pm 1.74$ & $173.6 \pm 0.5$ & $69.96 \pm 0.84$ & $170.8 \pm 1.1$ & $66.40 \pm 3.24$ & $174.4 \pm 0.2$ & $69.61 \pm 1.93$ & $171.6 \pm 0.5$ & $69.05 \pm 0.92$ \\
\hline & & 28 & $172.3 \pm 0.4$ & $69.74 \pm 1.73$ & $173.1 \pm 0.5$ & $70.91 \pm 3.95$ & $173.8 \pm 0.1$ & $70.21 \pm 0.79$ & $171.3 \pm 0.1$ & $69.74 \pm 0.45$ & $174.4 \pm 0.3$ & $69.87 \pm 1.11$ & $170.6 \pm 0.4$ & $66.55 \pm 5.38$ \\
\hline & & 100 & $172.8 \pm 0.4$ & $68.84 \pm 1.64$ & $173.7 \pm 0.2$ & $68.31 \pm 13$ & $172.3 \pm 1.1$ & $70.67 \pm 1.91$ & $172.1 \pm 1.2$ & $67.29 \pm 1.21$ & $173.9 \pm 0.4$ & $69.55 \pm 3.38$ & $172.2 \pm 0.2$ & $67.44 \pm 1.13$ \\
\hline & \multirow{4}{*}{30} & 0 & \multicolumn{6}{|c|}{ (NO) $\mathrm{T}_{\mathrm{M}}\left({ }^{\circ} \mathrm{C}\right)=175.2 \pm 0.1 \Delta \mathrm{h}_{\mathrm{M}}\left(\mathrm{Jg}^{-1}\right)=64.94 \pm 0.67$} & \multicolumn{6}{|c|}{ (YES) $\mathrm{T}_{\mathrm{M}}\left({ }^{\circ} \mathrm{C}\right)=173.7 \pm 0.1 \Delta \mathrm{h}_{\mathrm{M}}\left(\mathrm{Jg}^{-1}\right)=64.13 \pm 1.31$} \\
\hline & & 6 & $173.4 \pm 0.1$ & $61.54 \pm 1.93$ & $171.4 \pm 0.4$ & $62.22 \pm 0.8$ & $173.4 \pm 0.1$ & $60.87 \pm 2.46$ & $171.1 \pm 0.1$ & $61.92 \pm 1.34$ & $173.1 \pm 0.2$ & $62.21 \pm 3.96$ & $171.7 \pm 0.1$ & $55.82 \pm 4.32$ \\
\hline & & 28 & $172.8 \pm 0.1$ & $63.81 \pm 0.69$ & $171.8 \pm 0.7$ & $62.27 \pm 0.9$ & $172.5 \pm 0.1$ & $61.22 \pm 0.79$ & $171.7 \pm 0.2$ & $62.14 \pm 7.31$ & $173.1 \pm 0.2$ & $58.27 \pm 0.23$ & $171.7 \pm 0.4$ & $55.71 \pm 5.12$ \\
\hline & & 100 & $173.5 \pm 0.1$ & $59.22 \pm 0.57$ & $172.9 \pm 1.0$ & $59.75 \pm 0.55$ & $173.7 \pm 0.1$ & $60.67 \pm 1.82$ & $173.1 \pm 0.4$ & $63.69 \pm 1.48$ & $173.0 \pm 1.8$ & $59.21 \pm 2.94$ & $171.6 \pm 0.2$ & $6319 \pm 2.41$ \\
\hline
\end{tabular}

As can be seen, there was a $\sim 1-3^{\circ} \mathrm{C}$ reduction in crystallization temperature $T_{C}$, and $\sim 1$ $2{ }^{\circ} \mathrm{C}$ decrease in melting temperature $T_{M}$, for all materials at any test time. When it comes to enthalpies, there was a $\sim 20-25 \mathrm{~J} \mathrm{~g}^{-1}$ diminution of crystallization enthalpy $\left(\Delta h_{C}\right)$ and $\sim 10-15 \mathrm{~J} \mathrm{~g}^{-1}$ of melting enthalpy $\left(\Delta h_{M}\right)$, regardless the hydrothermal test temperature. Thus, the main changes occurred when the sampleswere submerged into water, regardless the temperature of the bath, so the PBHV biocomposites could thermally perform in a similar way up to saturation in a wide span of hydrothermal test temperatures.

\subsection{Surface effects}

Scanning Electron Microscopy (SEM) was used to assess the effect of water absorption at different hydrothermal test temperatures $T_{H}$ for all PHBV/sisal biocomposites. The influence of the amount of fibre is shown in Figure 9, where the surfaces of neat PHBV 
and biocomposites are compared for all $T_{H}$ at $100 \mathrm{~h}$ of testing. The PHBV matrix appeared eroded and rougher the higher the $T_{H}$ was. In addition, the higher the amount of fibre was, the lower the $T_{H}$ provoked defects on the surface, in terms of cracking. Actually, some large cracks appeared at high $T_{H}$. These results agree with those observed during the water absorption evaluation. The higher the amount of fibre, the faster the diffusion rate and the higher the water absorbed at saturation. The water was mainly incorporated into the fibre structures, swelling them and therefore causing an internal blow up of the PHBV matrixes. The fibres detached from the matrix, as is shown in Figure 10, where SEM pictures were taken closer. This figure shows the surface of PHBV and biocomposites at $160 \mathrm{~h}$ of the hydrothermal test carried out at $36^{\circ} \mathrm{C}$, as an example to explain the effect of the coupling agent. In general, both coupled and non-coupled biocomposites showed surface erosion, detachment of fibres and cracks, so it was discussed that the coupling agent was not a relevant factor in terms of preventing surface defects.

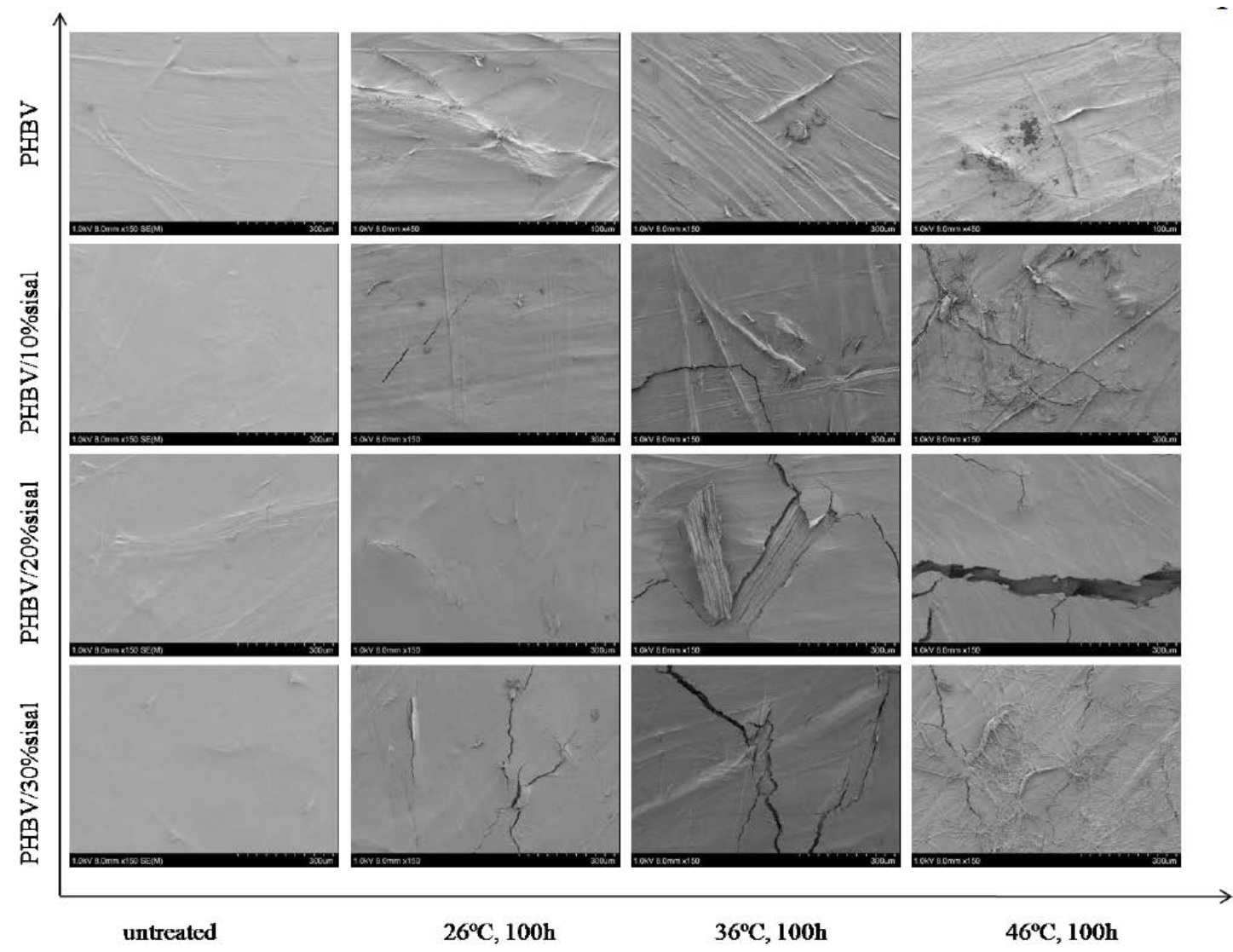

Figure 9.Comparison of SEM pictures of PHBV and PHBV/sisal composites untreated and at all

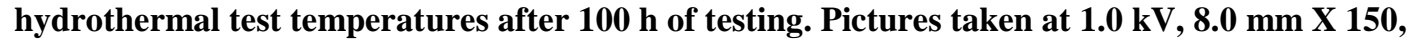
scale $=\mathbf{3 0 0}$ microns. 


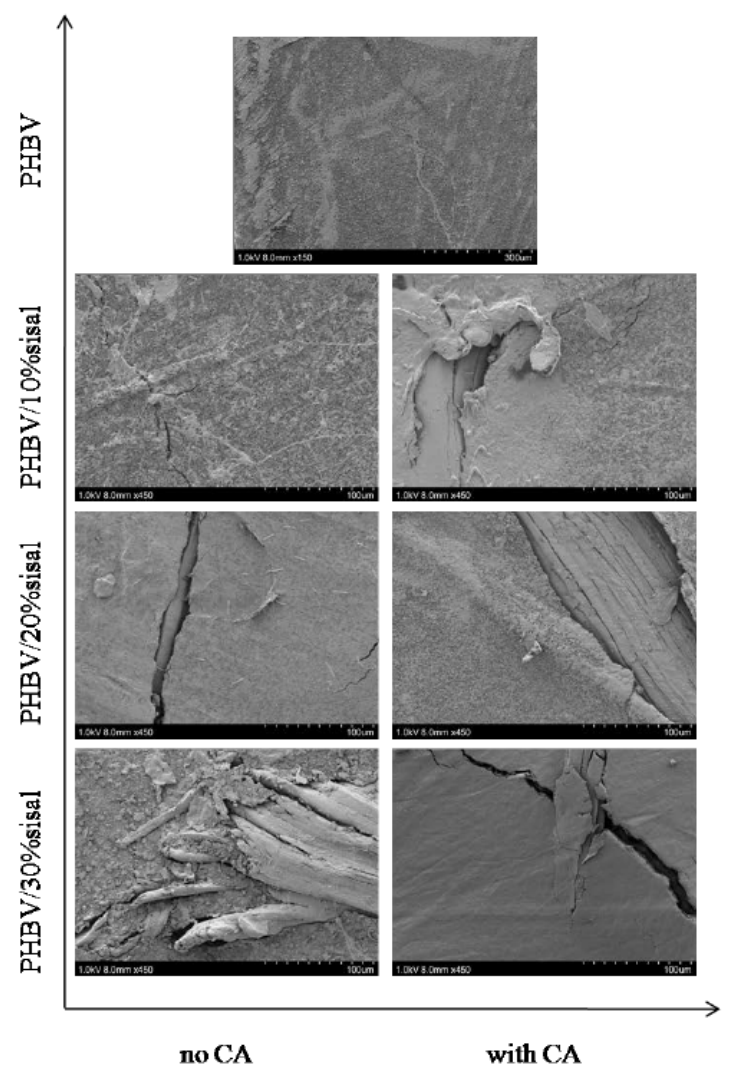

Figure 10.Comparison of SEM pictures of PHBV and coupled and non-coupled PHBV/sisal

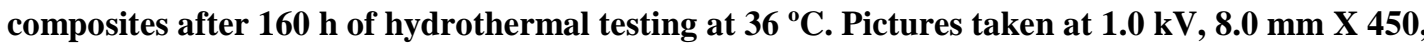
scale $=100$ microns.

\section{Conclusions}

The influence of percentage of fibre and the use of coupling agent was assessed for PHBV/sisal biocomposites in terms of water absorption behaviour, by focusing the analysis on the water absorption capability $\left(M_{S}\right)$ and water diffusion rate $(D)$, by means of hydrothermal testing at 26, 36 and $46{ }^{\circ} \mathrm{C}$.

It was found that both the higher the amount of sisal was present into the biocomposites and the higher the temperature of the test were, the faster the water got into the biocomposites (higher $D$ ) and the larger the amount of water was incorporated (higher $M_{S}$ ). Particularly, the percentage of fibre was more relevant in terms of water absorbed at saturation, and temperature more determinant in terms of water diffusion (higher $D$ ). The combination of sisal with coupling agent was relevant in terms of diffusion rate, due to chemical bonding between matrix and fibre, but not significant regarding the amount of water incorporated up to saturation, which was practically the same.

The performance of water-saturated biocomposites was physico-chemically assessed by FT-IR, SEC, DSC and SEM. In general terms, only fibre and temperature were relevant factors at this stage. It was found that the hydrothermal ambient reduced the molar mass of the biocomposites during immersion in water, but non-relevant differences among each temperature of the hydrothermal test were found. As well, only small variations of 
carbonyl index and thermal properties were recorded. SEM pictures showed the swelling of sisal fibres after water absorption, which provoked internal blow-up of the biocomposites for steric reasons and therefore cracks on the surface and fibre detaching.

\section{Acknowledgements}

The authors would like to acknowledge the Spanish Ministry of Economy and Competitiveness, through the Research Projects, UPOVCE-3E-013, ENE2011-28735C02-01, and the FPI-BES 2012-055316 pre-doctoral grants. GeneralitatValenciana is thanked for the GRISOLIA/2012/003, GRISOLIA/2013/036, APOSTD/2013/054, APOSTD/2013/036 and ACOMP/2013/143 programs. The Vice-rectorate for Research of UniversitatPolitècnica de València is also thanked for additional support through the PAID 05-09-4331, PAID-05-11/2806, PAID 06-11-2037 and PAID-06-SP20120581 projects.

\section{References}

1 Bledzki AK and Jaszkiewicz A. Composites Science and Technology. 2010, 70: 1687.

2 Kittikorn T, Stromberg , Karlsson S. Polymer from Renewable Resource 2012;3:79

3 Espert A, Camacho W, Karlsson S. Journal of Applied Polymer Science. 2003;89:2353

4 Xie Y, Hill CAS, Xiao Z, Militz H and Mai C. Composites: part A. 2010, 41: 806.

5 Nakatami H, Hashimoto K, Miyazaki K and Terano M. Journal of Applied Polymer Science. 2009, 113: 2022

6 Pettersson, L.; Oksman, K.; Mathew, AP. Journal of Applied Polymer Science. 2006, 102: 1852.

7 Avella, M.; Gaceva, GB.; Buzarovska, A.; Errico, ME.; Gentile, G.; Grozdanov, A. Journal of Applied Polymer Science. 2007, 104: 3192.

8 Ahmad EEM and LuytAS.Polymer composite. 2012, 33: 1205.

9. Bergeret A, Ferry L,Ienny P. Influence of the fibre/matrix interface on ageing mechanisms of glass fibre reinforced thermoplastic composites (PA-6,6, PET, PBT) in a hygrothermal environment. Polymer Degradation and Stability 2009; 94(9), 1315-1324.

10. Berthé V, Ferry L, Bénéze t JC, Bergeret A. Ageing of different biodegradablepolyesters blends mechanical and hygrothermalbehavior. Polymer Degradationand Stability 2010;95:262e9.

11. Badia JD, Santonja-Blasco L, Martínez-Felipe A, Ribes-Greus A. Hygrothermal ageing of reprocessed polylactide. Polymer Degradation \& Stability 2012;97(10):1881-90 
12. Proikakis CS, Ma mouzelos NJ, Tarantili PA, Andreopoulos AG. Swelling and hydrolytic degradation of poly(D, L-lactic acid) in aqueous solutions. Polymer Degradation and Stability 2006;91:614-619.

13. Saha SK, Tsuji H. Effects of molecular weight and small amounts of D-lactide units on hydrolytic degradation of poly(L-lactic acid)s. Polymer Degradation Stability 2006;91:1665-1673

14 J.S. Wiggins, M.K. Hassan, K.A. Mauritz, R.F. Storey Hydrolytic degradation of poly(D, L-lactide as a function of end group: carboxylic acid vs. hydroxyl]

15 E.V. de Paula, V. Mano, F.V. Pereira Influence of nanowhiskers on the hydrolytic degradation behavior of poly(D, L-lactide)])

16. Tang CY, Chen DZ, Yue TM, Chan KC, PeterT, Yu HF. Water absorption and solubility of PHBHV/HA nanocomposites, Composites Science and Technology 2008; 68 (7-8): 1927-1934

17.Li X, Liu KL, Wang M, Wong SY, Tjiu WC, He CH, Goh SH, Li J. Improving hydrophilicity, mechanical properties and biocompatibility of poly[(R)-3-hydroxybutyrate-co-(R)-3-hydroxyvalerate] through blending with poly[(R)-3-hydroxybutyrate]-alt-poly(ethylene oxide), ActaBiomaterialia 2009; 5(6) : 2002-2012

18. ISO62. Plastics-determination of water absorption; 2008.

19. ISO 291. Plastics e standard atmospheres for conditioning and testing; 1997.

20. Crank J, editor. The mathematics of diffusion. Oxford: Clarendon Press; 1975

21. Badia JD, Strömberg E, Ribes-Greus A, Karlsson S. A statistical design of experiments for optimizing the MALDI-TOF-MS sample preparation of polymers.an application in the assessment of the thermomechanical degradation mechanisms of poly (ethylene terephthalate). AnalyticaChimicaActa2011;692(12):85-95

22. Badia JD, Strömberg E, Ribes-Greus A, Karlsson S. Assessing the MALDI-TOF MS sample preparation procedure to analyze the influence of thermo-oxidative ageing and thermo-mechanical degradation on poly (lactide). European Polymer Journal 2011;47(7):1416-28

23. Badia JD, Strömberg E, Karlsson S, Ribes-Greus A. The role of crystalline, mobile amorphous and rigid amorphous fractions in the performance of recycled poly (ethylene terephthalate) (PET).Polymer Degradation \&Stability 2012;97(1):98-107

24. Badia JD, Strömberg E, Karlsson S, Ribes-Greus A. Material valorisation of amorphous polylactide. influence of thermo-mechanical degradation on the morphology, segmental dynamics, thermal and mechanical performance. Polymer Degradation \& Stability 2012;97(4):670-8.

25. Badia JD, Vilaplana F, Karlsson S, Ribes-Greus A. Thermal analysis as a quality tool for assessing the influence of thermo-mechanical degradation on recycled poly(ethylene terephthalate). Polymer Testing 2009;28(2):169-75 
26. Santonja-Blasco L, Moriana R, Badía JD, Ribes-Greus A. Thermal analysis applied to the characterization of degradation in soil of polylactide: I. calorimetric and viscoelastic analyses. Polymer Degradation \& Stability 2010;95(11):2192-9 
Search - Publisher copyright policies \& self-archiving

One journal found when searched for: 0141-3910

English | Español | Magyar | Português

\begin{tabular}{|c|c|}
\hline Paid OA: & A paid open access option is available for this journal. \\
\hline Author's Post-print: & $\checkmark$ author can archive post-print (ie final draft post-refereeing) \\
\hline Publisher's Version/PDF: & $\mathbf{X}$ author cannot archive publisher's version/PDF \\
\hline General Conditions: & 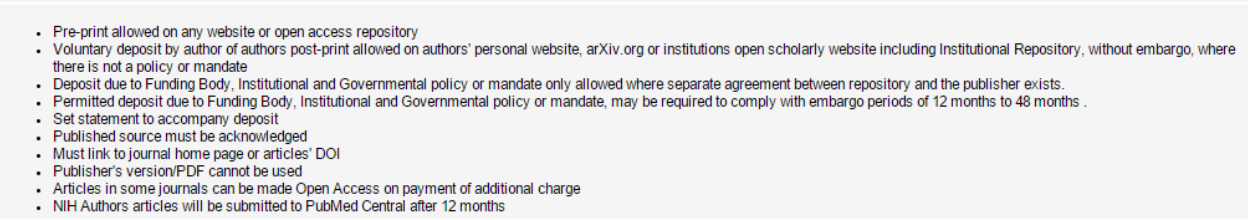 \\
\hline Mandated OA: & Compliance data is available for 57 funders \\
\hline Paid Open Access: & Open Access Articles \\
\hline
\end{tabular}

